
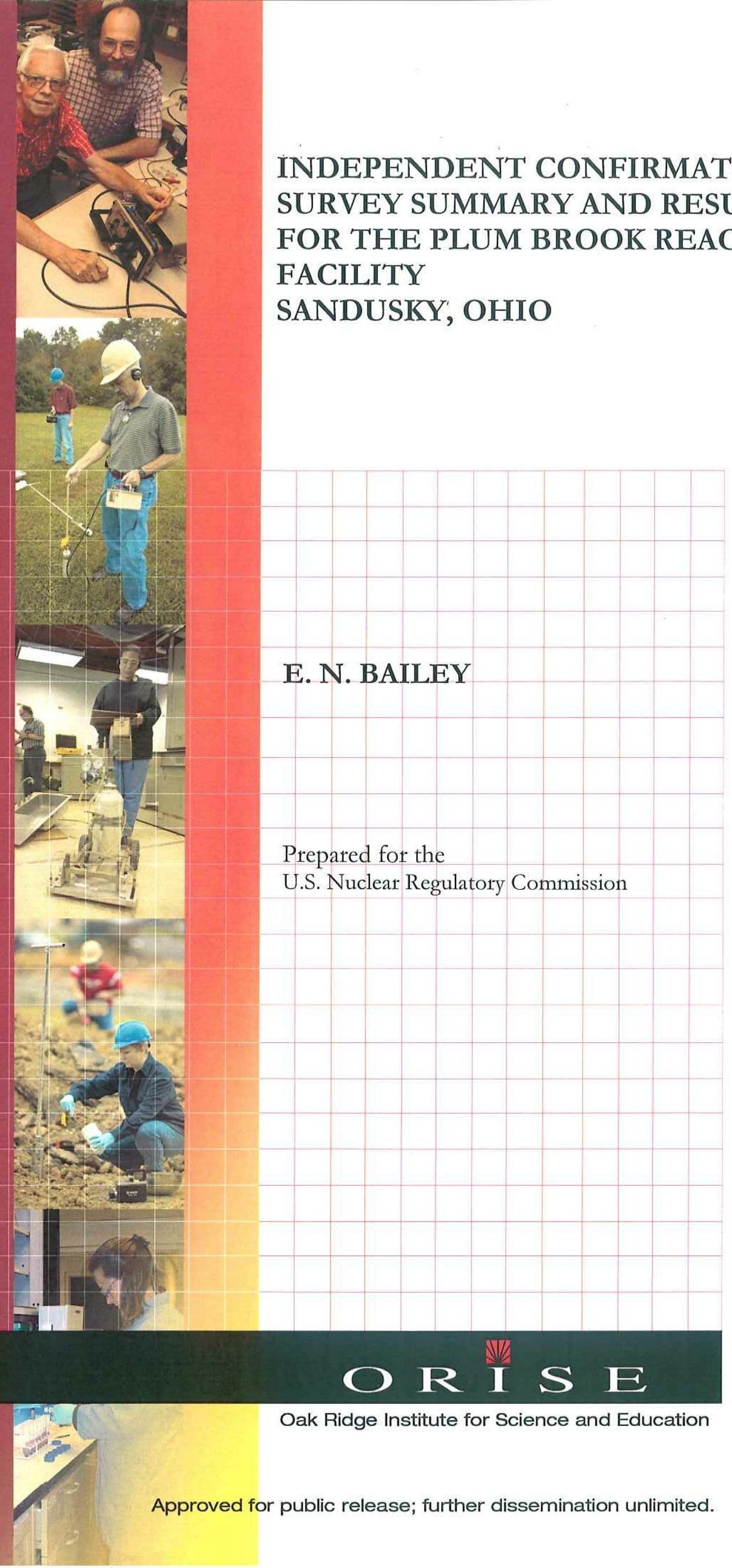

Oak Ridge Institute for Science and Education

Approved for public release; further dissemination unlimited. 
The Oak Ridge Institute for Science and Education (ORISE) is a U.S. Department of Energy facility focusing on scientific initiatives to research health risks from occupational hazards, assess environmental cleanup, respond to radiation medical emergencies, support national security and emergency preparedness, and educate the next generation of scientists. ORISE is managed by Oak Ridge Associated Universities. Established in 1946, ORAU is a consortium of 96 colleges and universities.

\section{NOTICES}

The opinions expressed herein do not necessarily reflect the opinions of the sponsoring institutions of Oak Ridge Associated Universities.

This report was prepared as an account of work sponsored by the United States Government. Neither the United States Government nor the U.S. Department of Energy, nor any of their employees, makes any warranty, expressed or implied, or assumes any legal liability or responsibility for the accuracy, completeness, or usefulness of any information, apparatus, product, or process disclosed, or represents that its use would not infringe on privately owned rights. Reference herein to any specific commercial product, process, or service by trade name, mark, manufacturer, or otherwise, does not necessarily constitute or imply its endorsement or recommendation, or favor by the U.S. Government or any agency thereof. The views and opinions of authors expressed herein do not necessarily state or reflect those of the U.S. Government or any agency thereof. 


\title{
INDEPENDENT CONFIRMATORY SURVEY SUMMARY AND RESULTS FOR THE \\ PLUM BROOK REACTOR FACILITY \\ SANDUSKY, OHIO
}

\author{
Prepared by \\ Erika N. Bailey \\ Oak Ridge Institute for Science and Education \\ Oak Ridge, Tennessee 37831-0017 \\ Prepared for the \\ U.S. Nuclear Regulatory Commission
}

FINAL REPORT

MAY 2008

This report is based on work performed under an Interagency Agreement (NRC Fin. No. J-5403) between the U.S. Nuclear Regulatory Commission and the U.S. Department of Energy. The Oak Ridge Institute for Science and Education performs complementary work under contract number DE-AC05-06OR23100 with the U.S. Department of Energy. 


\section{INDEPENDENT CONFIRMATORY SURVEY SUMMARY \\ AND RESULTS FOR THE \\ PLUM BROOK REACTOR FACILITY SANDUSKY, OHIO}

Prepared by: $\frac{\text { Cuia M. Balle }}{\text { E. N. Bailey, Project Leader }}$

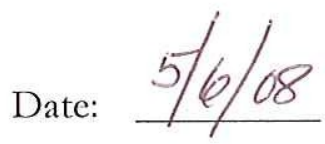

Reviewed by: $\frac{\text { Wmoth }}{\text { T. J. Vitkuof Survey Projects Manager }}$

Date: $5 / 2 / 2018$

Reviewed by: $\frac{\text { Nade l. Noy for }}{\text { R. D. Condra, Laborgtory Manager }}$

Date: $5 / 5 / 08$

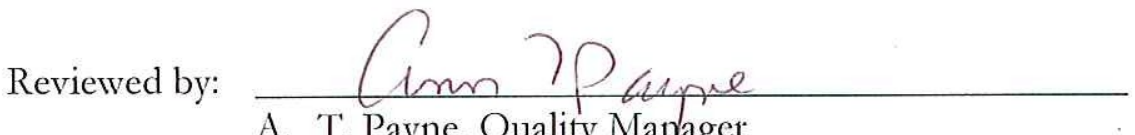

Date: $5 / 6 / 08$ 


\title{
ACKNOWLEDGMENTS
}

The author would like to acknowledge the significant contributions of the following staff members:

\section{FIELD STAFF}

T. D. Herrera

E. Montalvo

\section{LABORATORY STAFF}

R. D. Condra

J. S. Cox

W. P. Ivey

W. F. Smith

\section{CLERICAL STAFF}

R. M. Fink

K. M. Moore

A. Ramsey

\section{ILLUSTRATORS}

\author{
T. D. Herrera
}




\section{TABLE OF CONTENTS}

\section{PAGE}

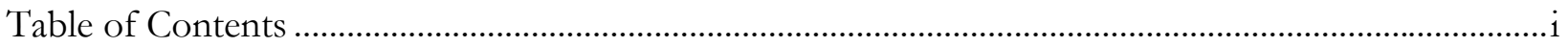

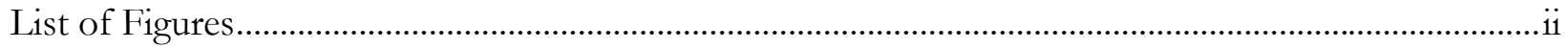

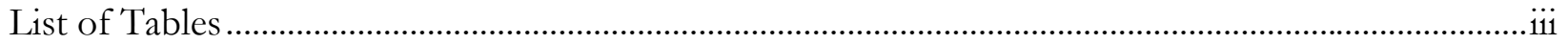

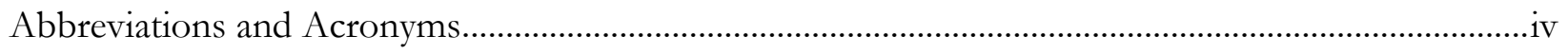

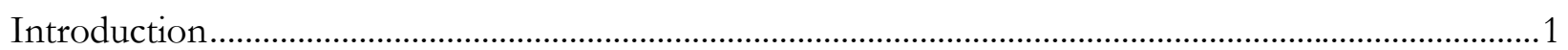

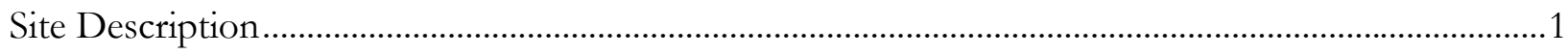

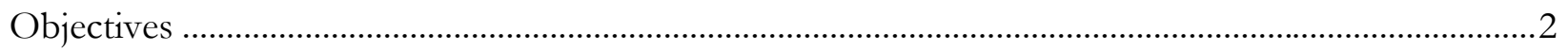

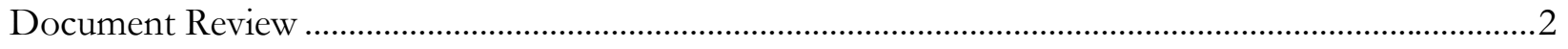

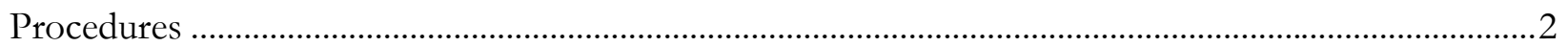

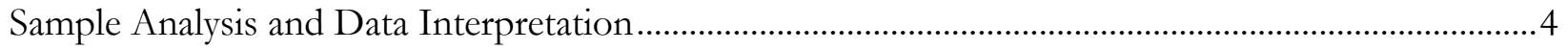

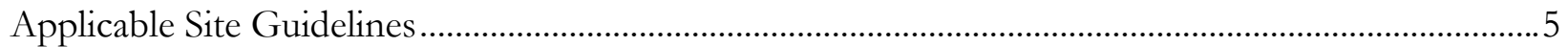

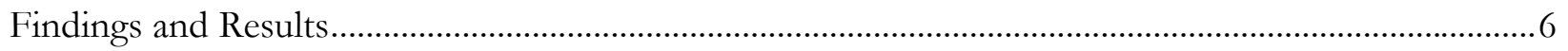

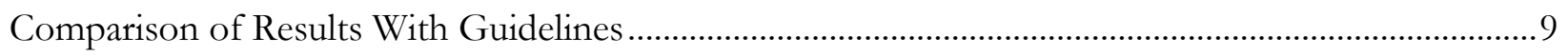

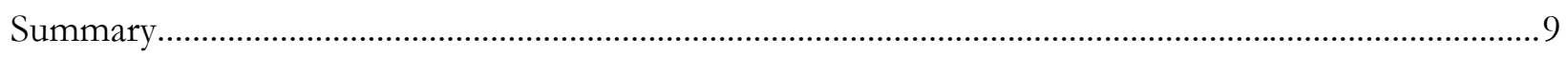

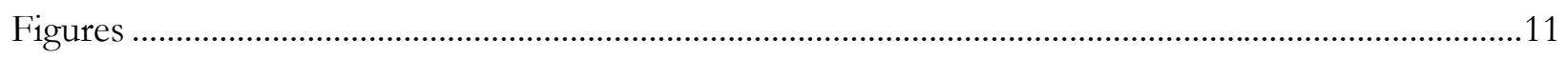

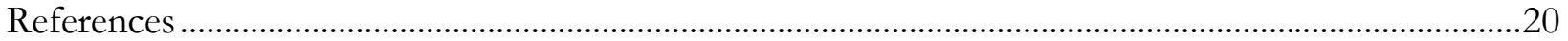

\section{APPENDICES:}

Appendix A: Major Instrumentation

Appendix B: Survey and Analytical Procedures 


\section{LIST OF FIGURES}

$\underline{\text { PAGE }}$

Figure 1: Plot Plan of the Plum Brook Reactor Facility ....................................................................12

Figure 2: Service and Equipment Building - Measurement and Sampling Locations .........................13

Figure 3: Reactor Office and Laboratory Building - Measurement and Sampling Locations .............14

Figure 4: Containment Vessel Sub-Pile Room and Hallway - Measurement and

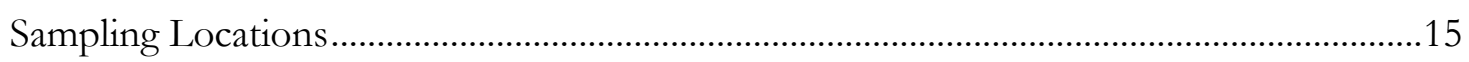

Figure 5: Reactor Office and Laboratory Building - Measurement and Sampling Locations .............16 


\section{LIST OF TABLES}

$\underline{\text { PAGE }}$

Table 1: Surface Activity Levels Plum Brook Reactor Facility Sandusky, Ohio ...................................18

Table 2: Surface Activity Data Comparison Plum Brook Reactor Facility Sandusky, Ohio ...............19 


\section{ABBREVIATIONS AND ACRONYMS}

\begin{tabular}{|c|c|}
\hline $\begin{array}{l}b_{i} \\
d^{\prime}\end{array}$ & $\begin{array}{l}\text { number of background counts in the interval } \\
\text { index of sensitivity }\end{array}$ \\
\hline$\varepsilon_{\mathrm{i}}$ & instrument efficiency \\
\hline$\varepsilon_{\mathrm{s}}$ & surface efficiency \\
\hline$\varepsilon_{\text {total }}$ & total efficiency \\
\hline $\mathrm{BKG}$ & background \\
\hline $\mathrm{cm}$ & centimeter \\
\hline $\mathrm{cm}^{2}$ & square centimeter \\
\hline cpm & counts per minute \\
\hline $\mathrm{CV}$ & Containment Vessel \\
\hline DCGL & derived concentration guideline value \\
\hline DCGL $_{\mathrm{GB}}$ & gross beta DCGL \\
\hline DCGL $_{W}$ & $\begin{array}{l}\text { DCGL for average concentrations over a wide area, used with } \\
\text { statistical tests }\end{array}$ \\
\hline $\mathrm{dpm} / 100 \mathrm{~cm}^{2}$ & disintegrations per minute per 100 square centimeters \\
\hline FSS & final status survey \\
\hline $\mathrm{H}-3$ & tritium \\
\hline IEAV & $\begin{array}{l}\text { Independent Environmental Assessment and Verification } \\
\text { Program }\end{array}$ \\
\hline ITP & Intercomparison Testing Program \\
\hline MAPEP & Mixed Analyte Performance Evaluation Program \\
\hline MARSSIM & Multi-Agency Radiation Survey and Site Investigation Manual \\
\hline $\mathrm{MDC}$ & minimum detectable concentration \\
\hline MDCR & minimum detectable count rate \\
\hline $\mathrm{MeV}$ & million electron volts \\
\hline $\mathrm{mg}$ & milligram \\
\hline $\min$ & minute \\
\hline $\mathrm{mm}$ & millimeter \\
\hline $\mathrm{mrem} / \mathrm{yr}$ & millirem per year \\
\hline $\mathrm{NaI}$ & sodium iodide \\
\hline NASA & National Aeronautics and Space Administration \\
\hline NIST & National Institute of Standards and Technology \\
\hline $\mathrm{NRC}$ & U.S. Nuclear Regulatory Commission \\
\hline NRIP & NIST Radiochemistry Intercomparison Program \\
\hline ORAU & Oak Ridge Associated Universities \\
\hline ORISE & Oak Ridge Institute for Science and Education \\
\hline PBRF & Plum Brook Reactor Facility \\
\hline $\mathrm{pCi}$ & picocuries \\
\hline ROLB & Reactor Office and Laboratory Building \\
\hline s & second \\
\hline SEB & Reactor Service and Equipment Building \\
\hline
\end{tabular}




\section{INDEPENDENT CONFIRMATORY SURVEY SUMMARY \\ AND RESULTS FOR THE \\ PLUM BROOK REACTOR FACILITY \\ SANDUSKY, OHIO}

\section{INTRODUCTION}

In 1941, the War Department acquired approximately 9,000 acres of land near Sandusky, Ohio and constructed a munitions plant. The Plum Brook Ordnance Works Plant produced munitions, such as TNT, until the end of World War II. Following the war, the land remained idle until the National Advisory Committee for Aeronautics (later known as the National Aeronautics and Space Administration or NASA) obtained 500 acres to construct a nuclear research reactor designed to study the effects of radiation on materials used in space flight. The research reactor was put into operation in 1961 and was the first of fifteen test facilities eventually built by NASA at the Plum Brook Station. By 1963, NASA had acquired the remaining land at Plum Brook for these additional test facilities.

After successfully completing the objective of landing humans on the Moon and returning them safely to Earth, NASA was faced with budget reductions from Congress in 1973. These budgetary constraints caused NASA to cease operations at several research facilities across the country, including those at Plum Brook Station. The major test facilities at Plum Brook were maintained in a standby mode, capable of being reactivated for future use. The Plum Brook Reactor Facility (PBRF) was shut down January 5,1973 and all of the nuclear fuel was eventually removed and shipped off site to a U.S. Department of Energy facility in Idaho for disposal or reuse. Decommissioning activities are currently underway at the PBRF (NASA 1999).

\section{SITE DESCRIPTION}

The Plum Brook Station is south of the town of Sandusky, Ohio and is surrounded by farmlands and low density residential housing. Approximately 5,400 acres of the Plum Brook Station are enclosed within a security fence. Individual security fences surround several of the test sites including the PBRF. The PBRF consists of numerous buildings within a 27 acre fenced area (NASA 2005). The Plum Brook Station is named for the creek that runs through the site. 


\section{OBJECTIVES}

The objectives of the confirmatory survey activities were to provide independent contractor field data reviews and to generate independent radiological data for use by the Nuclear Regulatory Commission (NRC) in evaluating the adequacy and accuracy of the licensee's procedures and final status survey (FSS) results.

\section{DOCUMENT REVIEW}

Prior to onsite activities, the Oak Ridge Institute for Science and Education (ORISE) was tasked with reviewing NASA's FSS Plan, specifically, the technical basis for the derived concentration guideline levels (NASA 2007a). ORISE also reviewed the licensee's survey design/survey request packages and limited final status radiological survey data for the areas of the buildings selected for confirmatory survey activities. The licensee's survey methodology document was also reviewed (NASA 2007b). All documents and data were reviewed for adequacy and appropriateness taking into account the Plum Brook Decommissioning Plan, FSS Plan, and Multi-Agency Radiation Survey and Site Investigation Manual (MARSSIM) guidance (NASA 2005, NASA 2007a and NRC 2000).

\section{PROCEDURES}

A survey team from ORISE visited the PBRF site from February 5 through 7, 2008 to perform visual inspections and measurement and sampling activities. Confirmatory survey activities were conducted in accordance with a site-specific survey plan, the ORISE/IEAV Survey Procedures Manual and Quality Program Manual (ORISE 2008a, 2008b and ORAU 2007).

Survey units are classified based on contamination potential, as either Class 1, 2, or 3 in accordance with MARSSIM (NRC 2000). A description of each is as follows:

Class 1: $\quad$ Buildings or land areas that have a significant potential for radioactive contamination (based on site operating history) or known contamination (based on previous radiological surveys) that exceeds the expected derived concentration guideline value $\left(\mathrm{DCGL}_{\mathrm{W}}\right)$. 
Class 2: $\quad$ Buildings or land areas, often contiguous to Class 1 areas, that have a potential for radioactive contamination but at levels less than the expected $\mathrm{DCGL}_{\mathbb{W}}$.

Class 3: $\quad$ Remaining impacted buildings and land areas that are not expected to contain residual contamination, or are expected to contain levels of residual contamination at a small fraction of the DCGL $\mathrm{W}_{\mathrm{W}}$.

Confirmatory survey activities were conducted in the Cold Pipe Tunnel within the Reactor Service Equipment Building (SEB), Class 1 Areas within the Reactor Office and Laboratory Building (ROLB) including the Chemical Laboratory and the basement, and the Sub-Pile Room and hallway within the Containment Vessel (CV). Instrument comparison measurements were also performed within the SEB.

\section{REFERENCE SYSTEM}

Measurements and sampling locations were referenced to prominent site features and documented on site drawings provided by the licensee.

\section{SURFACE SCANS}

Scans were performed using sodium iodide $(\mathrm{NaI})$ scintillation detectors for direct gamma radiation and gas proportional detectors for direct alpha plus beta radiation, coupled to ratemeters or ratemeter-scalers with audible indicators.

The licensee's findings were considered when determining the level of survey effort required. Floors were scanned for alpha plus beta radiation and in limited instances gamma radiation. Lower walls and accessible upper surfaces were scanned for alpha plus beta radiation. The surface scan coverage of the areas selected for confirmatory surveys varied based on the size and accessibility of the areas. The total area covered was dependent upon results as the survey progressed. Scans were focused in areas where the licensee had identified contamination and/or performed remediation and other conspicuous areas. Particular attention was given to surfaces where material may have accumulated such as cracks and joints in the floor and walls, ledges, and other horizontal surfaces. 


\section{Surface ACtivity MeAsurements}

Direct measurements to quantify total alpha and beta activity levels were performed at judgmental locations and locations with elevated radiation levels identified by surface scans. In each of the areas selected for survey, a direct measurement was performed at the location exhibiting the highest radiation level identified by ORISE. Direct measurements were made using gas proportional detectors coupled to ratemeter-scalers. Two smear samples were collected from each direct measurement location, one to determine removable gross alpha and gross beta activity levels and one to quantify tritium (H-3). Measurement locations are illustrated on Figures 2 through 5.

Questions and concerns were brought to the immediate attention of the NRC representatives and the licensee and are also noted in the Findings and Results section of this report.

\section{Surface ACTIVITy DATa CoMparison}

ORISE performed direct beta measurements at three locations for direct measurement data comparison alongside licensee technicians while they were performing FSS activities in the SEB Mezzanine. However, the licensee's measurement data contained in this report are not the FSS data that will be reported by the licensee for these locations. These measurements were re-performed at a later date. Radiation levels within the SEB Mezzanine had been reduced to nearly background levels through remediation. Although ORISE prefers to perform instrument/data comparison measurements at numerous locations exhibiting a range of activities (background to elevated levels), the measurements were still collected for comparative informational purposes.

\section{SAMPLE ANALYSIS AND DATA INTERPRETATION}

Samples were returned to the ORISE laboratory in Oak Ridge, Tennessee for analysis and interpretation. Sample analyses were performed in accordance with the ORISE Laboratory Procedures Manual (ORISE 2008d). Smear samples collected for the quantification of gross alpha/beta activity were analyzed using a low-background proportional counter. Smear samples collected for the quantification of H-3 were analyzed using a liquid scintillation analyzer. Smear sample and direct measurement results are reported in units of disintegrations per minute per one-hundred square centimeters $\left(\mathrm{dpm} / 100 \mathrm{~cm}^{2}\right)$. 
The data generated were compared with the approved derived concentration guideline levels (DCGL $L_{\mathbb{W}} \mathrm{s}$ ) established for the PBRF site.

\section{APPLICABLE SITE GUIDELINES}

The primary contaminants of concern at the PBRF facility are beta-gamma emitters-fission and activation products-resulting from reactor operation. Alpha contamination has been identified in specific areas of the site.

The DCGL $\mathrm{W}_{\mathbb{W}}$ values for structures are listed below. The DCGL ${ }_{\mathrm{w}}$ values are the surface activity levels in $\mathrm{dpm} / 100 \mathrm{~cm}^{2}$ that will be used to evaluate FSS measurements to determine compliance with the $25 \mathrm{mrem} / \mathrm{yr}$ unrestricted use criterion.

\section{DCGLw Values for Structures}

\begin{tabular}{||c|c|}
\hline Radionuclide & DCGL $_{\mathrm{w}} \mathbf{( d p m / 1 0 0 \mathbf { c m } ^ { 2 } )}$ \\
\hline \hline Co-60 & 11,000 \\
\hline Sr-90 & 33,100 \\
\hline Cs-137 & 40,500 \\
\hline Eu-154 & 4,500 \\
\hline H-3 & $9.1 \mathrm{E}+06$ \\
\hline $\mathrm{I}-129$ & 14,900 \\
\hline $\mathrm{U}-234$ & 31,500 \\
\hline $\mathrm{U}-235$ & 27,100 \\
\hline $\mathrm{U}-236$ & 33,200 \\
\hline
\end{tabular}

During site characterization activities the licensee determined the specific radionuclides that were present at the site. Radionuclide mixtures to be used during FSS planning were determined using the sample analyses of concrete cores, smears, and other media samples. In areas of the buildings where multiple radionuclides were present, the licensee calculated gross beta $\mathrm{DCGL}_{\mathrm{GB}}$ values. This approach enables field measurements of gross activity rather than the determination of individual radionuclide activity for comparison to the radionuclide-specific DCGL $\mathrm{W}_{\mathbb{W}}$ (NASA 2007a). 
The gross beta DCGL ${ }_{\mathrm{GB}}$ values were calculated using the following equation:

$$
D C G L_{G B}=\frac{1}{\left(\frac{f_{1}}{D C G L_{W 1}}\right)+\left(\frac{f_{2}}{D C G L_{W 2}}\right)+\left(\frac{f_{3}}{D C G L_{W 3}}\right)+\left(\frac{f_{n}}{D C G L_{W n}}\right)}
$$

Where: DCGL $_{\mathrm{GB}}=$ gross beta DCGL

$\mathrm{f}_{\mathrm{n}}=$ mixture fraction of radionuclide " $\mathrm{n}$ " and

$\mathrm{DCGL}_{\mathbb{W}_{\mathrm{n}}}=\mathrm{DCGL}_{\mathrm{W}}$ of radionuclide "n"

The gross beta DCGL ${ }_{\mathrm{GB}}$ values for the areas selected for confirmatory survey activities are listed below (NASA 2007b).

\section{DCGLgb Values and Radionuclide Fractions for Structures}

\begin{tabular}{|c|c|c|c|c|c|c|c|c|c|}
\hline \multirow{2}{*}{ Building } & \multirow{2}{*}{$\begin{array}{c}\text { DCGL }_{\mathrm{GB}} \\
\left(\mathrm{dpm} / 100 \mathrm{~cm}^{2}\right)\end{array}$} & \multicolumn{8}{|c|}{ Radionuclide Fraction used to Calculate DCGL ${ }_{\mathrm{GB}}{ }^{\text {a }}$} \\
\hline & & H-3 & Сo-60 & Sr-90 & I-129 & Cs-137 & Eu-154 & U-234 & U-235 \\
\hline $\begin{array}{l}\text { SEB Cold Pipe Tunnel } \\
\text { (Class } 1 \text { Areas) }\end{array}$ & 11,000 & 0 & 1.0 & 0 & 0 & 0 & 0 & 0 & 0 \\
\hline $\begin{array}{l}\text { ROLB Chemical Laboratory } \\
\text { (Class } 1 \text { Areas) }\end{array}$ & 27,166 & 0.2707 & 0.0965 & 0.0788 & 0.0142 & 0.4671 & 0.0012 & 0.0698 & 0.0017 \\
\hline $\begin{array}{l}\text { ROLB Basement } \\
\text { (Class } 1 \text { Areas) }\end{array}$ & 27,166 & 0.2707 & 0.0965 & 0.0788 & 0.0142 & 0.4671 & 0.0012 & 0.0698 & 0.0017 \\
\hline $\begin{array}{l}\text { CV Sub-Pile Room and } \\
\text { Hallway (Class } 1 \text { Areas) }\end{array}$ & 14,600 & 0.0729 & 0.5389 & 0.2222 & 0 & 0.1205 & 0.0171 & 0.0242 & 0.0042 \\
\hline
\end{tabular}

aH-3 and I-129, the hard-to-detect radionuclides, were addressed by using Cs-137 as the surrogate. In instances where H-3 and I-129 were present, the Cs-137 DCGL was scaled using the surrogate DCGL formula in the Adjusted Gross DCGLs for Structural Surfaces Technical Basis Document (NASA 2007b).

Removable activity guidelines were set at $10 \%$ or less of the $\mathrm{DCGL}_{\mathbb{W}}$ values consistent with the assumptions made during structural dose modeling development (NASA 2007a).

\section{FINDINGS AND RESULTS}

The results for each of the verification activities are discussed below. 


\section{DOCUMENT REVIEW}

The ORISE reviews of NASA's project documentation indicated that most procedures and methods implemented for the FSS were appropriate and that the resultant data were acceptable. Comments identified during the review of the technical basis for DGCL development in the final status survey plan were provided to the NRC (ORISE 2008c). The limited FSS data packages that were reviewed accurately and adequately described the sequence of FSS activities and the radiological conditions at the site. Other observations identified during the site visit are addressed below.

During onsite activities the licensee provided ORISE their survey design/survey request packages for each of the areas selected for confirmatory survey activities. The gross beta DCGL ${ }_{\mathrm{GB}}$ values varied across the site, therefore, the scan investigation levels for both the hand-held and the floor monitor detectors also varied from area to area. The survey request packages were very useful in providing specific instructions and guidelines to the technicians performing the FSS activities. However, while reviewing these packages, ORISE identified that the licensee's floor monitor scan investigation levels were set too high. The NRC and the licensee were notified of the issue. During the site closeout meeting, ORISE explained that the floor monitor issue results from the use of the total surface area of a large area distributed source for efficiency determination during calibration. Guidelines are based on $100 \mathrm{~cm}^{2}$ and it is a fact that a small, high-activity point source could fall below the investigation level determined by the licensee (using the efficiencies determined from the large area distributed source) but be above the DCGL. The licensee stated that their documented scan procedure is to perform static measurements using the hand-held detectors at any locations identified by the floor monitor exhibiting an increase in activity. However, upon further review of NASA's procedures, it was determined by ORISE that the documented scan procedure did not reflect what was indicated to the NRC and ORISE as their procedure during the closeout meeting. NASA's Procedure 4.3.2 - Scan Measurements for Beta/Gamma and Alpha Surface Activity, is general in terms of specific detectors; therefore, in addition to hand-held detectors the applicability of this procedure to the floor monitor detector (Ludlum model 43-37) is also assumed (NASA 2007c). This being the case, the procedure says "IF the activity exceeds THE SURFACE SCAN INVESTIGATION LEVEL established by the SR (survey request), THEN perform the following: 1), 2), 3) OBTAIN STATIC MEASUREMENTS...." Further concern resulted from a location that ORISE specifically noted on the floor in the Chemical Lab of the ROLB (location 6) because it was 
well below the licensee's floor monitor scan investigation level of $16,000 \mathrm{cpm}$ with activity of approximately 5,000 cpm. However, the direct measurement at this location with a hand-held detector of 5,632 cpm resulted in 22,349 dpm/100 $\mathrm{cm}^{2}$ (gross activity) which is just below the DCGL $_{\mathrm{GB}}$ of $27,166 \mathrm{dpm} / 100 \mathrm{~cm}^{2}$. Extrapolation of this example indicates that values below the $16,000 \mathrm{cpm}$ scan investigation level could result in activity greater than the $\mathrm{DCGL}_{\mathrm{GB}}$. The findings were presented in an email to the NRC who indicated they would further discuss the issue with the licensee (ORISE 2008e).

Following issuance of the ORISE findings, the licensee suspended the use of the floor monitor detectors until the findings could be resolved and corrective actions implemented. The licensee first performed testing using a smaller $100 \mathrm{~cm}^{2}$ source and confirmed that the PBRF scan action levels used to perform final status surveys in the ROLB and SEB were set too high to identify small high-activity point sources. The resolution implemented by the licensee was the calculation of revised (lower) floor monitor scan action levels that would account for smaller areas of activity (100 $\mathrm{cm}^{2}$ ) that would exceed the DCGL. The licensee confirmed the new action levels through a series of instrument source checks and efficiency determinations. In addition, the licensee opted to rescan all Class 2 and Class 3 floor surfaces within the ROLB and SEB using the new investigation levels. The licensee reported that the rescans did not identify activity greater than the new investigation levels. To prevent recurrence of this error, all FSS/Characterization Engineers were briefed and the licensee entered the issue into their corrective action database for tracking and recording (NASA 2008).

\section{SURFACE SCANS}

Surface scans of the selected areas within the SEB Cold Pipe Tunnel, Class 1 Areas within the ROLB including the Chemical Laboratory and the basement, and the Sub-Pile Room and hallway within the CV identified beta radiation greater than background levels but did not identify any locations exhibiting residual beta surface contamination in excess of the respective $\mathrm{DCGL}_{\mathrm{GB}}$.

\section{SurfaCE ACTIVIty MEASUREMENTS}

Total surface activity and removable activity levels are provided in Table 1. The surface activity values reported represent gross surface activity levels that have not been corrected for background 
contributions to be consistent with the conservative approach being taken by the licensee. In each of the areas selected for survey, a direct measurement was performed at the location exhibiting the highest radiation level identified by ORISE. Total activity ranged from 1,500 to $22,000 \mathrm{dpm} / 100 \mathrm{~cm}^{2}$. Removable activity ranged from 0 to $5 \mathrm{dpm} / 100 \mathrm{~cm}^{2}$ for gross alpha and -5 to $14 \mathrm{dpm} / 100 \mathrm{~cm}^{2}$ for gross beta. Removable tritium activity ranged from -2 to $142 \mathrm{dpm} / 100 \mathrm{~cm}^{2}$.

\section{SurfaCE ACTIVITy DATA COMPARISON}

The ORISE surface activity levels for the comparison data set ranged from 640 to $890 \mathrm{dpm} / 100 \mathrm{~cm}^{2}$; and the licensee's surface activity levels ranged from 1,140 to $2,450 \mathrm{dpm} / 100 \mathrm{~cm}^{2}$. The data clearly indicate that the licensee's surface activity levels collected from the same locations are higher. Upon further review, the major difference results from a surface efficiency factor that the licensee applies for surface irregularity. This is a conservative approach applied when calculating the gross activity values. If ORISE were to apply a similar surface efficiency value, the measurements would be more closely comparable. The surface activity data comparison results are presented in Table 2.

\section{COMPARISON OF RESULTS WITH GUIDELINES}

Total surface activity values were directly compared with the gross beta DCGL ${ }_{\mathrm{GB}}$ values developed by the licensee. All values were less than the corresponding $\mathrm{DCGL}_{\mathrm{GB}}$. Removable activity results were well below $10 \%$ of the DCGL $\mathrm{D}_{\mathrm{W}}$ values. These data confirm the licensee's FSS results.

\section{SUMMARY}

At the request of the U.S. Nuclear Regulatory Commission, the Oak Ridge Institute for Science and Education conducted confirmatory surveys of the Plum Brook Reactor Facility during the period of February 5 through 7,2008. The survey activities included visual inspections and measurement and sampling activities. Confirmatory activities also included the review and assessment of the licensee's project documentation.

The licensee provided a thorough response regarding the immediate action and the steps taken in the resolution of the floor monitor scan action level finding (NASA 2008). The ultimate resolution 
included the calculation of revised (lower) floor monitor scan action levels that would account for a smaller area of activity $\left(100 \mathrm{~cm}^{2}\right)$ that would exceed the $\mathrm{DCGL}_{\mathrm{GB}}$, which is a conservative approach to ensure that the DCGLs would not be exceeded when the technicians refer to these values.

The FSS data packages that were reviewed accurately and adequately described the sequence of FSS activities and the radiological conditions at the site. All confirmatory measurement results were below the respective derived gross beta guideline levels for the radionuclides of concern as specified in the Final Status Survey Plan (NASA 2007a). Removable activity results were well below 10\% of the DCGL $\mathrm{W}_{\mathrm{W}}$ values. ORISE's radiological survey data confirm that the radiological conditions of the portions of the survey units that were surveyed were commensurate with the $\mathrm{DCGL}_{\mathrm{GB}}$ values cited in the licensee's technical basis document (NASA 2007b). Confirmatory survey activities validated the licensee's conclusions regarding each area's classification, final radiological status, and that the guidelines have been satisfied. 


\section{FIGURES}




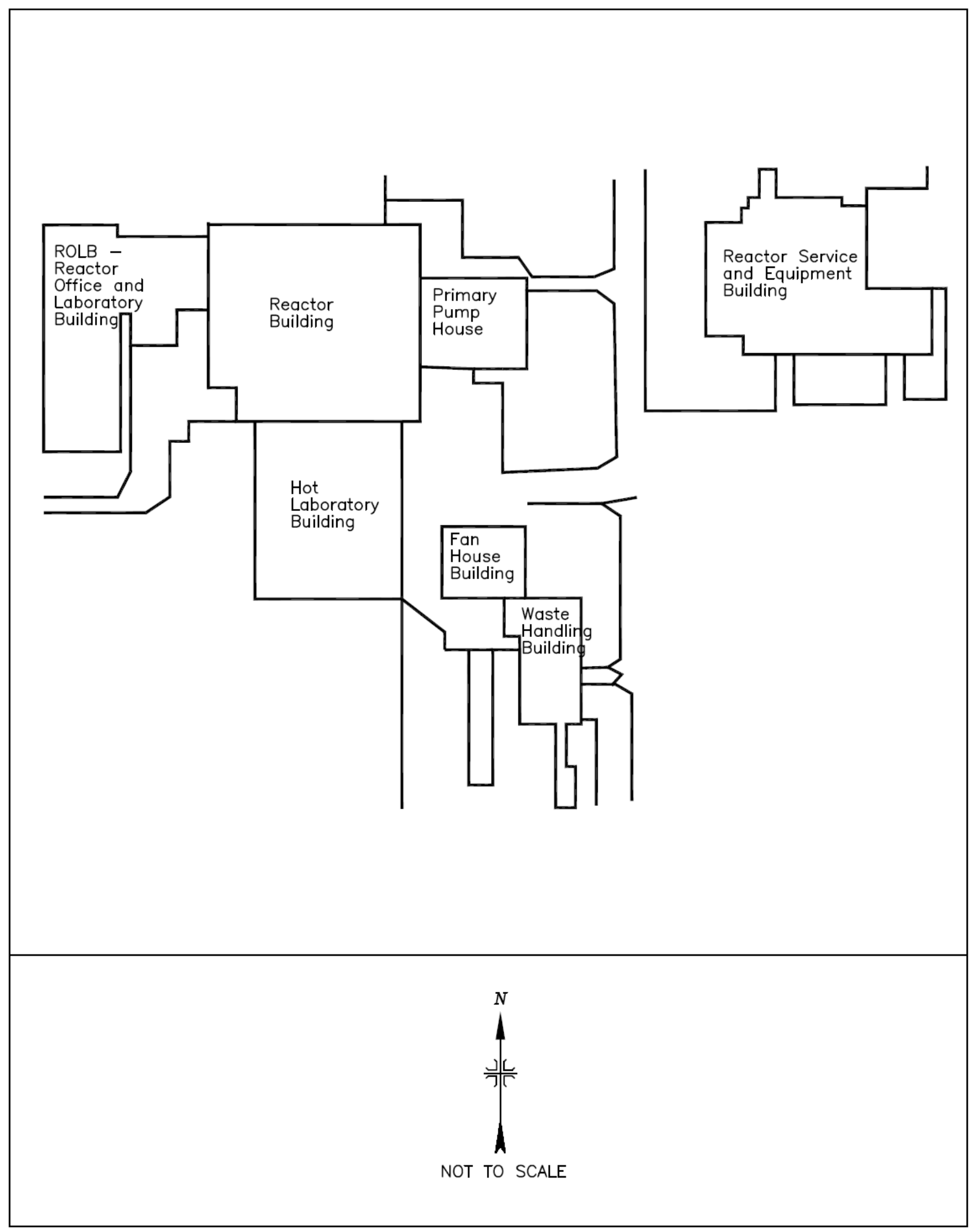

FIGURE 1: PLOT PLAN OF THE PLUM BROOK REACTOR FACILITY 


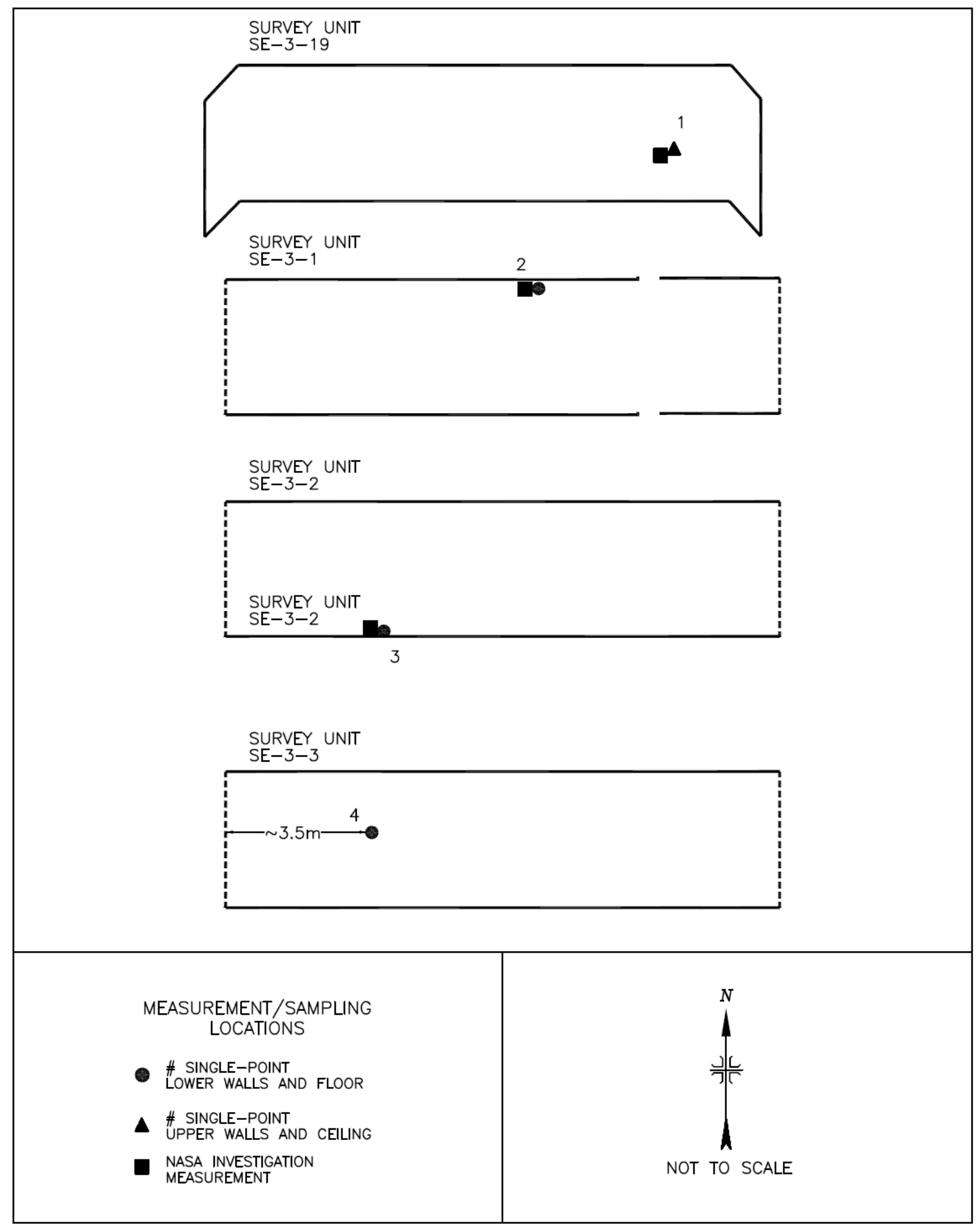

FIGURE 2: SERVICE AND EQUIPMENT BUILDING - MEASUREMENT AND SAMPLING LOCATIONS 


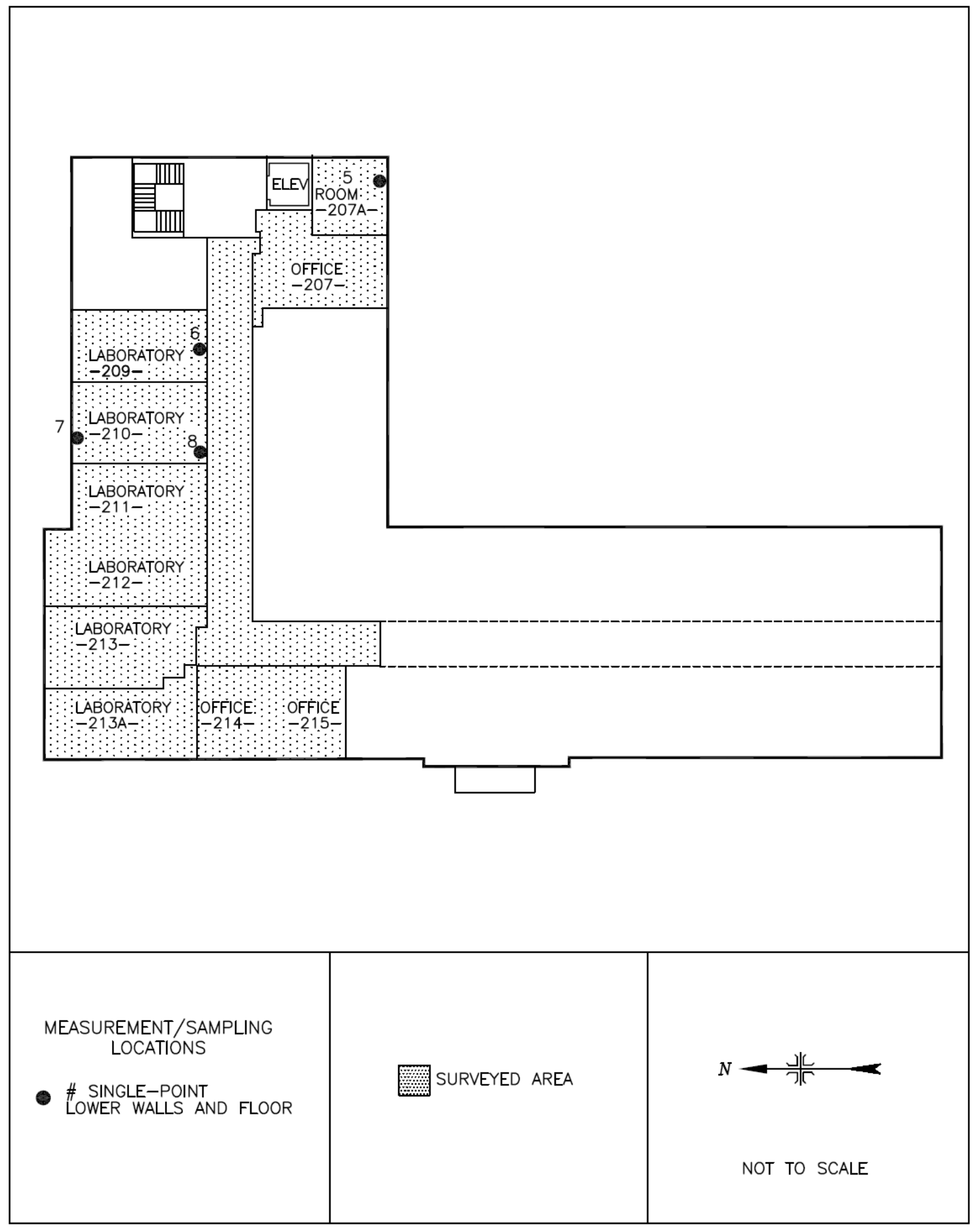

FIGURE 3: REACTOR OFFICE AND LABORATORY BUILDING - MEASUREMENT AND SAMPLING LOCATIONS 


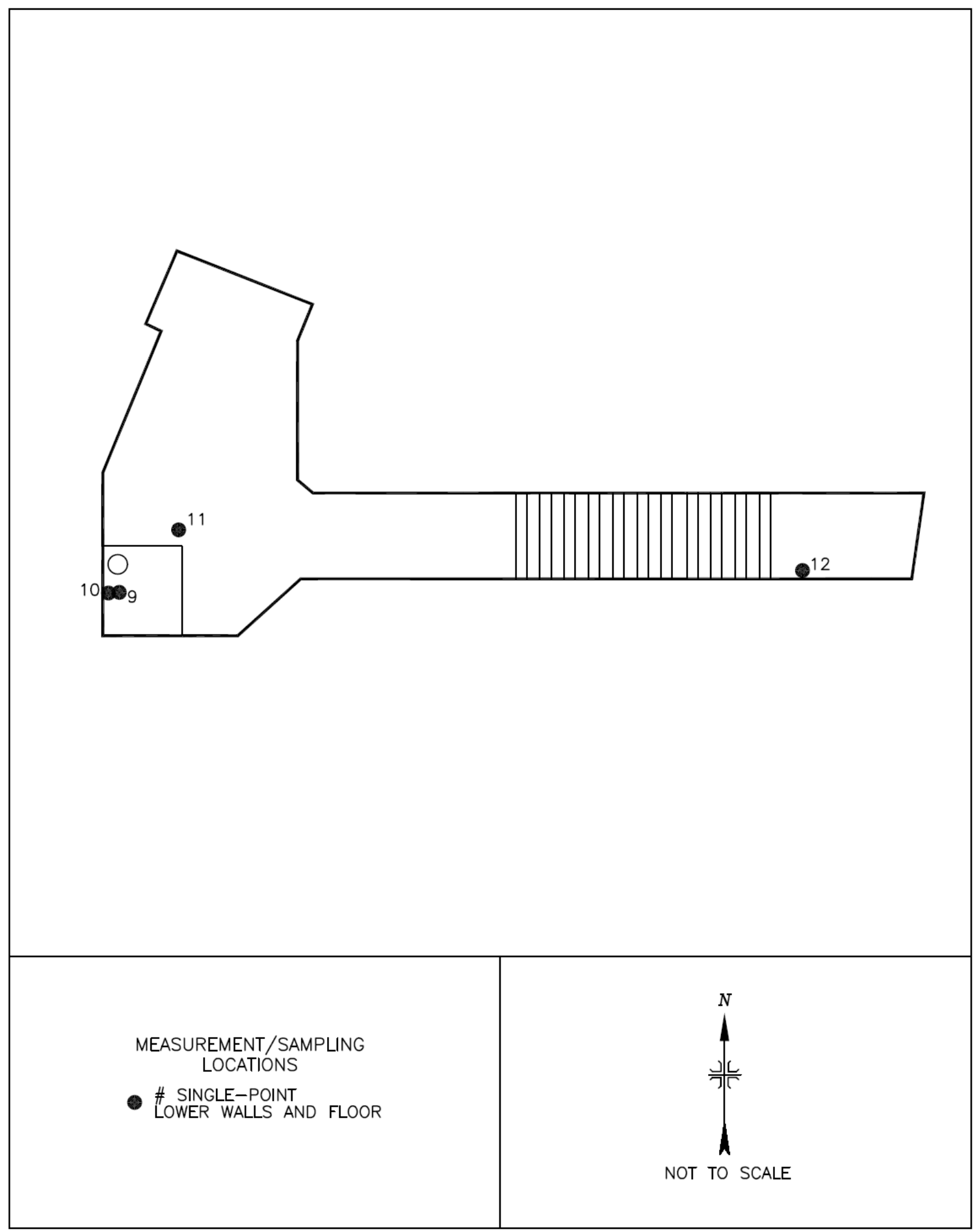

FIGURE 4: CONTAINMENT VESSEL SUB-PILE ROOM AND HALLWAY MEASUREMENT AND SAMPLING LOCATIONS 


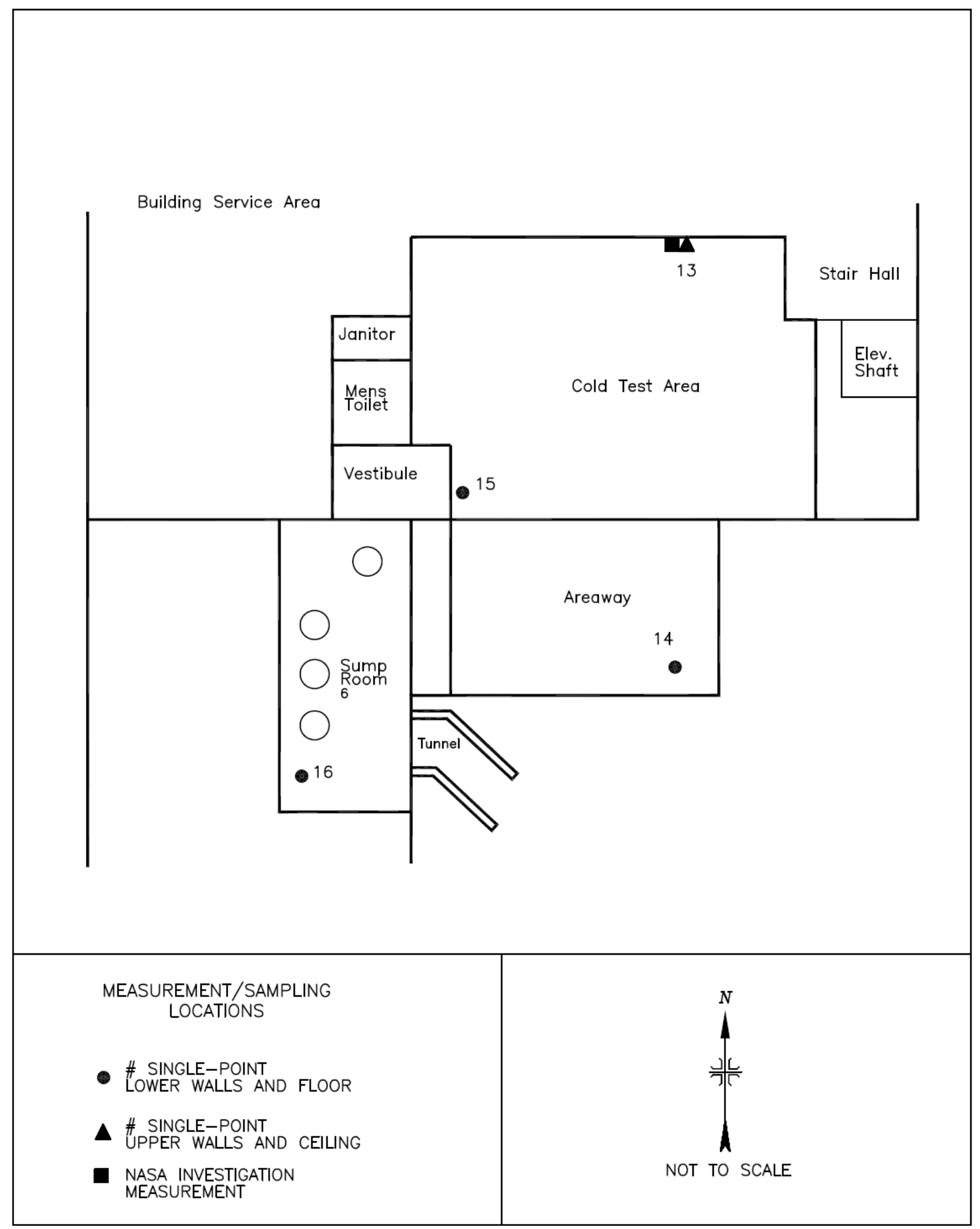

FIGURE 5: REACTOR OFFICE AND LABORATORY BUILDING - MEASUREMENT AND SAMPLING LOCATIONS 


\section{TABLES}


TABLE 1

SURFACE ACTIVITY LEVELS

PLUM BROOK REACTOR FACILITY

SANDUSKY, OHIO

\begin{tabular}{|c|c|c|c|c|c|}
\hline \multirow{2}{*}{$\begin{array}{c}\text { Building (Class) } \\
\text { Measurement } \\
\text { Location }^{\mathrm{a}}\end{array}$} & \multirow{2}{*}{ Surface $^{b}$} & \multirow{2}{*}{$\begin{array}{l}\begin{array}{l}\text { Total Activity } \\
\left(\mathrm{dpm} / 100 \mathrm{~cm}^{\mathrm{c}}\right)\end{array} \\
\text { Alpha plus Beta }\end{array}$} & \multicolumn{3}{|c|}{$\begin{array}{l}\text { Removable Activity } \\
\left(\mathrm{dpm} / 100 \mathrm{~cm}^{2}\right)\end{array}$} \\
\hline & & & Alpha & Beta & H-3 \\
\hline \multicolumn{6}{|c|}{ SEB Cold Pipe Tunnel (1) } \\
\hline 1 & US & 10,000 & 0 & 9 & 13 \\
\hline 2 & $\mathrm{~F}$ & 6,000 & 0 & 4 & 23 \\
\hline 3 & $\mathrm{~F}$ & 9,200 & 1 & 1 & -2 \\
\hline 4 & $\mathrm{~F}$ & 5,000 & 0 & -2 & -1 \\
\hline \multicolumn{6}{|c|}{ ROLB Chemical Laboratory (1) } \\
\hline 5 & $\mathrm{~F}$ & 1,500 & 0 & 1 & 5 \\
\hline 6 & $\mathrm{~F}$ & 22,000 & 1 & 14 & 12 \\
\hline 7 & $\mathrm{~F}$ & 10,000 & 3 & -2 & 18 \\
\hline 8 & $\mathrm{~F}$ & 3,000 & 0 & -2 & 26 \\
\hline \multicolumn{6}{|c|}{ CV Sub-Pile Room and Hallway (1) } \\
\hline 9 & $\mathrm{~F}$ & 3,700 & 1 & 7 & 4 \\
\hline 10 & $\mathrm{LW}$ & 5,000 & 1 & 4 & 42 \\
\hline 11 & $\mathrm{~F}$ & 5,800 & 1 & -1 & 13 \\
\hline 12 & $\mathrm{~F}$ & 3,900 & 0 & 4 & 16 \\
\hline \multicolumn{6}{|c|}{ ROLB Basement (1) } \\
\hline 13 & US & 17,000 & 0 & 11 & 142 \\
\hline 14 & $\mathrm{~F}$ & 7,600 & 1 & -5 & 3 \\
\hline 15 & $\mathrm{~F}$ & 5,000 & 5 & 1 & 3 \\
\hline 16 & $\mathrm{~F}$ & 9,200 & 1 & 3 & 33 \\
\hline
\end{tabular}

${ }^{a}$ Refer to Figures 2 through 5.

${ }^{b} \mathrm{~F}=$ floor, $\mathrm{LW}=$ lower wall, US=upper surface.

cData represent gross surface activity levels that have not been corrected for background contributions. Total Activity results were rounded to two significant figures.

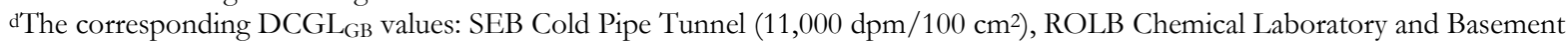
$\left(27,166 \mathrm{dpm} / 100 \mathrm{~cm}^{2}\right)$, CV Sub-Pile Room and Hallway $\left(14,600 \mathrm{dpm} / 100 \mathrm{~cm}^{2}\right)$. 
TABLE 2

\section{SURFACE ACTIVITY DATA COMPARISON \\ PLUM BROOK REACTOR FACILITY SANDUSKY, OHIO}

\begin{tabular}{|c|c|c|c|}
\hline \multirow{2}{*}{ Location $^{\mathbf{a}}$} & \multirow{2}{*}{ Surface $^{\mathrm{b}}$} & \multicolumn{2}{|c|}{$\begin{array}{c}\text { Total Beta Activity } \\
\left(\mathbf{d p m} / \mathbf{1 0 0} \mathbf{c m}^{\mathbf{2}} \mathbf{)}\right.\end{array}$} \\
\cline { 3 - 4 } & & ORISEc $^{\mathbf{c}}$ & NASA $^{\mathbf{d}}$ \\
\hline \hline SM8 & FL & 890 & 2,454 \\
\hline SM9 & LW & 640 & 1,138 \\
\hline SM11 & LW & 720 & 1,175 \\
\hline
\end{tabular}

${ }^{a}$ NASA FSS static measurement locations.

${ }^{\mathrm{b} F L}=$ floor; $\mathrm{LW}=$ lower wall

cORISE data represent gross surface activity levels that have not been corrected for background contributions. Total Beta Activity results were rounded to two significant figures.

dNASA Total Beta Activity results and information were provided by NASA. Data represent gross surface activity levels that have not been corrected for background contributions. 


\section{REFERENCES}

NASA Plum Brook Reactor Facility (NASA). The History of NASA's Plum Brook Station. Sandusky, Ohio; June 1999.

NASA Plum Brook Reactor Facility. Decommissioning Plan for the Plum Brook Reactor Facility, Revision 5. Sandusky, Ohio; December 2005.

NASA Plum Brook Reactor Facility. Final Status Survey Plan for the Plum Brook Reactor Facility, Revision 1. Sandusky, Ohio; February 2007a.

NASA Plum Brook Reactor Facility. Adjusted Gross DCGLs for Structural Surfaces PBRF-TBD07-001. Revision 0. Sandusky, Ohio; June 5, 2007b.

NASA Plum Brook Reactor Facility. Survey Methodology to Support PBRF License Termination CS-01. Revision 2. Sandusky, Ohio; September 17, 2007c.

NASA Plum Brook Reactor Facility. Email from John Thomas to William Snell, Erika Bailey and Chad Glenn; Re: Response to ORISE Inspection Issue. Sandusky, Ohio; April 22, 2008.

Oak Ridge Associated Universities (ORAU). Quality Program for the Independent Environmental Assessment and Verification Program. Oak Ridge, Tennessee; November 1, 2007.

Oak Ridge Institute for Science and Education (ORISE). Radiation Protection Plan. Oak Ridge, Tennessee; September 10, 2005.

Oak Ridge Institute for Science and Education. Final Confirmatory Survey Plan for the Plum Brook Reactor Facility, Sandusky, Ohio 1760-PL-01-1. Oak Ridge, Tennessee; January 30, 2008 a.

Oak Ridge Institute for Science and Education. Survey Procedures Manual for the Independent Environmental Assessment and Verification Program. Oak Ridge, Tennessee; January 18, $2008 \mathrm{~b}$.

Oak Ridge Institute for Science and Education. Document Review of the DCGL Technical Basis in the Final Status Survey Plan for the Plum Brook Reactor Facility, Sandusky, Ohio. Oak Ridge, Tennessee; January 7, 2008c.

Oak Ridge Institute for Science and Education. Laboratory Procedures Manual for the Environmental Survey and Site Assessment Program. Oak Ridge, Tennessee; March 3, 2008d.

Oak Ridge Institute for Science and Education. Email from Erika Bailey sent to William Snell; Re: More on the Plum Brook Action Level. Oak Ridge, Tennessee; February 15, 2008e.

U.S. Nuclear Regulatory Commission (NRC). Multi-Agency Radiation Survey and Site Investigation Manual (MARSSIM), NUREG-1575; Revision 1. Washington, DC; August 2000. 
APPENDIX A

\section{MAJOR INSTRUMENTATION}




\section{APPENDIX A}

\section{MAJOR INSTRUMENTATION}

The display of a specific product is not to be construed as an endorsement of the product or its manufacturer by the author or her employer.

\section{SCANNING INSTRUMENT/DETECTOR COMBINATIONS}

\section{Alpha plus Beta}

Ludlum Floor Monitor Model 239-1

combined with

Ludlum Ratemeter-Scaler Model 2221

coupled to

Ludlum Gas Proportional Detector Model 43-37, Physical Area: $550 \mathrm{~cm}^{2}$

(Ludlum Measurements, Inc., Sweetwater, TX)

Ludlum Ratemeter-Scaler Model 2221

coupled to

Ludlum Gas Proportional Detector Model 43-68, Physical Area: $126 \mathrm{~cm}^{2}$

(Ludlum Measurements, Inc., Sweetwater, TX)

\section{$\underline{\text { Gamma }}$}

Ludlum Pulse Ratemeter Model 12

(Ludlum Measurements, Inc., Sweetwater, TX)

coupled to

Victoreen NaI Scintillation Detector Model 489-55, Crystal: $3.2 \mathrm{~cm}$ x $3.8 \mathrm{~cm}$

(Victoreen, Cleveland, $\mathrm{OH}$ )

\section{Direct MEASurement Instrument/Detector Combinations}

\section{Alpha plus Beta}

Ludlum Ratemeter-Scaler Model 2221

coupled to

Ludlum Gas Proportional Detector Model 43-68, Physical Area: $126 \mathrm{~cm}^{2}$

(Ludlum Measurements, Inc., Sweetwater, TX) 


\section{LABORATORY ANALYTICAL INSTRUMENTATION}

Low-Background Gas Proportional Counter Model LB-5100-W

(Tennelec/Canberra, Meriden, CT)

Tri-Carb Liquid Scintillation Analyzer

Model 3100

(Packard Instrument Co., Meriden, CT) 
APPENDIX B

SURVEY AND ANALYTICAL PROCEDURES 


\section{APPENDIX B}

\section{SURVEY AND ANALYTICAL PROCEDURES}

\section{Project Health AND SAFETy}

The proposed survey and sampling procedures were evaluated to ensure that any hazards inherent to the procedures themselves were addressed in current job hazard analyses. Prior to onsite activities, a pre-job integrated safety management checklist was completed and discussed with field personnel.

Additionally, upon arrival on site, a walk-down of the site was performed to identify hazards present. All survey and laboratory activities were conducted in accordance with ORISE health and safety and radiation protection procedures (ORISE 2005).

\section{QuAlity Assurance}

Analytical and field survey activities were conducted in accordance with procedures from the following documents:

- Survey Procedures Manual (January 1, 2008)

- Laboratory Procedures Manual (March 3, 2008)

- Quality Program Manual (November 1, 2007)

The procedures contained in these manuals were developed to meet the requirements of Department of Energy Order 414.1C and the U.S. Nuclear Regulatory Commission Quality Assurance Manual for the Office of Nuclear Material Safety and Safeguards and contain measures to assess processes during their performance.

Calibration of all field and laboratory instrumentation was based on standards/sources, traceable to NIST. Quality control procedures include:

- Daily instrument background and check-source measurements to confirm that equipment operation is within acceptable statistical fluctuations.

- Participation in MAPEP, NRIP, and ITP Laboratory Quality Assurance Programs.

- Training and certification of all individuals performing procedures.

- Periodic internal and external audits. 


\section{Calibration Procedures}

Detectors used for assessing surface activity were calibrated in accordance with ISO-7503 ${ }^{1}$ recommendations. Total alpha plus beta efficiencies $\left(\varepsilon_{\text {total }}\right)$ were determined for each instrument/detector combination and consisted of the product of the $2 \pi$ instrument efficiency $\left(\varepsilon_{i}\right)$ and surface efficiency $\left(\varepsilon_{\mathrm{s}}\right): \varepsilon_{\text {total }}=\varepsilon_{\mathrm{i}} \times \varepsilon_{\mathrm{s}}$.

Tc-99 was selected as the beta calibration source. The $2 \pi$ beta instrument efficiency $\left(\varepsilon_{i}\right)$ factor for the gas proportional detector used to collect direct measurements was 0.40 . ISO-7503 recommends an $\varepsilon_{\mathrm{s}}$ of 0.5 for maximum beta energies greater than $0.4 \mathrm{MeV}$ (beta energy of Cs-137 is greater than $0.4 \mathrm{MeV}$ ). The total beta efficiency was 0.20 .

\section{SuRVEY Procedures}

\section{$\underline{\text { Surface Scans }}$}

Structural surface scans were performed by passing the detectors slowly over the surface while the distance between the detector and the surface was maintained at a minimum. A large surface area $\left(550 \mathrm{~cm}^{2}\right)$ gas proportional floor monitor with a $0.8 \mathrm{mg} / \mathrm{cm}^{2}$ window was used to scan the floors of the surveyed areas and in limited instances a $\mathrm{NaI}$ scintillation detector was also used. Wall surfaces were scanned using small area $\left(126 \mathrm{~cm}^{2}\right)$ hand-held detectors with a $0.8 \mathrm{mg} / \mathrm{cm}^{2}$ window. Identification of elevated radiation levels was based on increases in the audible signal from the recording and/or indicating instrument.

Beta surface scan minimum detectable concentrations (MDCs) were estimated using the calculational approach described in NUREG-1507. ${ }^{2}$ The scan MDC is a function of many variables, including the background level. Additional parameters selected for the calculation of scan MDCs included a two-second observation interval, a specified level of performance at the first scanning stage of $95 \%$ true positive rate and $25 \%$ false positive rate, which yields a $d$ 'value of 2.32 (NUREG-1507, Table 6.1), and a surveyor efficiency of 0.5. The beta total efficiency was 0.20 .

\footnotetext{
${ }^{1}$ International Standard. ISO 7503-1, Evaluation of Surface Contamination - Part 1: Beta-emitters (maximum beta energy greater than 0.15 MeV) and alpha-emitters. August 1, 1988.

2NUREG-1507. Minimum Detectable Concentrations With Typical Radiation Survey Instruments for Various Contaminants and Field Conditions. US Nuclear Regulatory Commission. Washington, DC; June 1998.
} 
To illustrate an example for a hand-held gas proportional detector using the instrument background of $399 \mathrm{cpm}$, the minimum detectable count rate (MDCR) and scan MDC can be calculated as follows:

$$
\begin{aligned}
& \mathrm{b}_{\mathrm{i}}=(399 \mathrm{cpm})(2 \mathrm{~s})(1 \mathrm{~min} / 60 \mathrm{~s})=6.65 \text { counts } \\
& \operatorname{MDCR}=(2.32)(6.65 \mathrm{counts})^{1 / 2}[(60 \mathrm{~s} / \mathrm{min}) /(2 \mathrm{~s})]=359 \mathrm{cpm} \\
& \operatorname{MDCR}_{\text {surveyor }}=359 /(0.5)^{1 / 2}=508 \mathrm{cpm}
\end{aligned}
$$

The scan MDC is calculated using the beta total efficiency of 0.20 .

$$
\text { ScanMDC }=\frac{M D C R_{\text {surveyor }}}{\left(\varepsilon_{s}\right)\left(\varepsilon_{i}\right)} d p m / 100 \mathrm{~cm}^{2}
$$

For the given background, the estimated scan MDC was 2,540 dpm/100 $\mathrm{cm}^{2}$ for the hand-held gas proportional detector.

The identification of elevated radiation levels that could exceed the site criteria was determined based on an increase in the audible signal from the indicating instrument.

Specific scan MDCs for the NaI scintillation detector were not determined as the instrument was used solely as a qualitative means to identify elevated gamma activity.

\section{Surface Activity Measurements}

Measurements of total beta surface activity levels were performed using hand-held gas proportional detectors coupled to portable ratemeter-scalers. Count rates (cpm), which were integrated over one minute with the detector held in a static position, were converted to activity levels $\left(\mathrm{dpm} / 100 \mathrm{~cm}^{2}\right)$ by dividing the count rate by the total static efficiency $\left(\varepsilon_{\mathrm{i}} \times \varepsilon_{\mathrm{s}}\right)$ and correcting for the physical area of the detector. ORISE did not determine construction material-specific background for each surface type encountered for determining net count rates. Instead, ORISE took the conservative approach being used by the licensee and did not subtract material specific backgrounds in determining surface activity levels. 
The a priori $\mathrm{MDC}$ for surface activity measurements was calculated using the following equation:

$$
M D C=\frac{3+(4.65 \sqrt{B})}{T x \varepsilon_{T o t} x G}
$$

Where:

$$
\begin{array}{lll}
\mathrm{B} & = & \text { background (total counts) in time interval, } \mathrm{T} \\
\mathrm{T} & = & \text { count time (min) used for field instruments } \\
\varepsilon_{\mathrm{Tot}} & = & \text { total efficiency }=\varepsilon_{\mathrm{i}} \mathrm{x} \varepsilon_{\mathrm{s}} \\
\varepsilon_{\mathrm{i}} & = & \text { instrument efficiency } \\
\varepsilon_{\mathrm{s}} & = & \text { source efficiency } \\
\mathrm{G} & = & \text { geometry (physical detector area } \left.\mathrm{cm}^{2} / 100\right)
\end{array}
$$

The a priori beta static MDC was approximately $380 \mathrm{dpm} / 100 \mathrm{~cm}^{2}$ using the total efficiency of 0.20 instrument background of $399 \mathrm{cpm}$. The physical surface area assessed by the gas proportional detector used was $126 \mathrm{~cm}^{2}$.

\section{$\underline{\text { Removable Activity Measurements }}$}

Removable gross alpha and gross beta activity levels were determined using numbered filter paper disks, $47 \mathrm{~mm}$ in diameter. Moderate pressure was applied to the smear and approximately $100 \mathrm{~cm}^{2}$ of the surface was wiped. Smears were placed in labeled envelopes with the location and other pertinent information recorded.

For tritium determinations, a second smear was moistened with deionized water and an adjacent $100 \mathrm{~cm}^{2}$ was wiped. The smear was then sealed in a labeled liquid scintillation vial with the location and pertinent information recorded.

\section{RADIOLOGICAL ANALYSIS}

\section{Gross Alpha/Beta}

Smears were counted on a low-background gas proportional system for gross alpha and beta activity. The MDCs of the procedure were $9 \mathrm{dpm} / 100 \mathrm{~cm}^{2}$ and $15 \mathrm{dpm} / 100 \mathrm{~cm}^{2}$ for a 2 -minute count time for gross alpha and gross beta, respectively. 


\section{Liquid Scintillation}

Analyses for tritium were performed by placing a smear or a representative portion of the samples into scintillation cocktail and counting on a liquid scintillation analyzer. Samples were then spiked with a known amount of the appropriate standard and recounted. The typical MDC of the procedure is $5 \mathrm{pCi}$ for smears.

\section{Detection Limits}

Detection limits, referred to as minimum detectable concentration (MDC), were based on 3 plus 4.65 times the standard deviation of the background count $\left[3+\left(4.65(\mathrm{BKG})^{1 / 2}\right)\right]$. Because of variations in background levels, measurement efficiencies, and contributions from other radionuclides in samples, the detection limits differ from sample to sample and instrument to instrument. 